\title{
An Unusual Clinical Presentation of Amyloidosis: Auricular Concha Involvement
}

OMER KARADAG, MD, Associate Professor; TUGBA AKIN, MD; A. IHSAN ERTENLI, MD, Professor, Hacettepe University Faculty of Medicine - Division of Rheumatology, Hacettepe University, Ankara, Turkey. Address correspondence to Dr. Karadag, Hacettepe University, Tip Fakultesi Romatoloji Bilim Dali, 06100 Sihhiye, Ankara, Turkey. E-mail: omerk@ hacettepe.edu.tr. J Rheumatol 2014;41:140; doi:10.3899/jrheum.130689

The most serious complication in familial Mediterranean fever (FMF) is the development of amyloidosis. Amyloid deposition can be systemic or organ-specific.

A 31-year-old Turkish man was admitted with upper gastrointestinal bleeding and hematuria. He had recurrent attacks of abdominal pain and fever since early childhood. Nine years before, AA amyloidosis was detected in a renal biopsy. He was diagnosed with FMF and colchicine treatment was started. Physical examination revealed markedly thickened skin in each ear in the area of concha and amyloid nodules (Figure 1), echymotic skin lesions on lumbar area and legs (no trauma reported), and painless massive splenomegaly palpable up to the pelvis. Bone

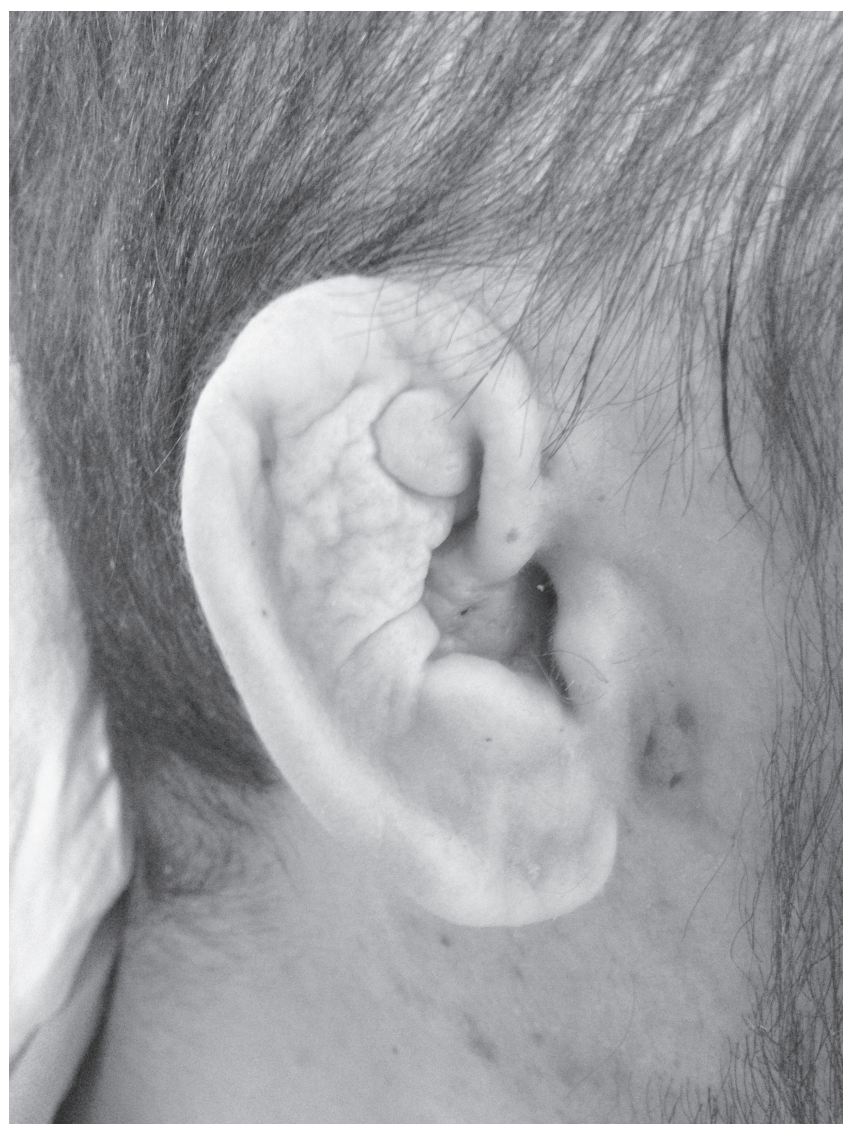

Figure 1. Markedly thickened skin in each ear in the area of the concha and amyloid nodules. marrow aspiration and biopsy revealed normocellularity of the marrow and deposition of amyloid in the walls of the blood vessels. Laboratory tests revealed hemoglobin level of $8.8 \mathrm{~g} / \mathrm{dl}$, white blood (cell) count of $9000 / \mathrm{mm}^{3}$, platelet count of $41,000 / \mathrm{mm}^{3}$, and homozygous M694V alleles. Other causes of bleeding disorders were excluded. Nosocomial infections led to septic shock and death.

Amyloidosis of the auricular concha is a rare variant of primary localized cutaneous amyloidosis ${ }^{1}$. It has not been previously reported in systemic amyloidosis. Patients with FMF can have clinical features such as refractory cytopenia and bleeding disorders. Amyloid angiopathy with increased fragility of blood vessels and impaired vasoconstriction may promote bleeding ${ }^{2}$.

\section{REFERENCES}

1. Shimauchi T, Shin JH, Tokura Y. Primary cutaneous amyloidosis of the auricular concha: case report and review of published work. J Dermatol 2006;33:128-31.

2. Sucker C, Hetzel GR, Grabensee B, Stockschlaeder M, Scharf RE. Amyloidosis and bleeding: pathophysiology, diagnosis, and therapy. Am J Kidney Dis 2006;47:947-55. 